\title{
Perceptions of Indonesian Citizenship Teachers on Teaching Tolerance in Schools through Citizenship Education
}

\author{
Asep Rudi Casmana \\ Citizenship Education Studies, Global and International Department of Education \\ The University of York \\ York, United Kingdom \\ aseprudi83@gmail.com
}

\begin{abstract}
This study examines the teacher's perception of teaching tolerance within citizenship education in Indonesia. It seeks to identify the teachers' opinion about the purpose of teaching tolerance, and the content knowledge and the teaching method used by citizenship teachers to educate students to be more tolerant. It adopts a mixed method design by combining quantitative and qualitative methods. As such, 103 online questionnaires were collected, using Qualtrics software and using a snowball sampling technique. In addition, ten teachers were interviewed using online telephone interviews to get more details about the reasons for supporting teaching tolerance using a convenience sampling technique. Descriptive statistic, frequency distribution and cross tabulation analysis, using SPSS, and coding method on NVivo were used to analyse the results of this research. The results indicate that there are three main reasons for teaching tolerance, which are: to let students make interreligious and inter-ethnic friendships; to prevent disruptive or violent behaviour in class; and to reduce discrimination among students who are of different ethnic and religious backgrounds. In order to achieve these goals and effectively teach tolerance within citizen education, human rights, a sense of personal identity and a sense of community involvement are suggested as appropriate content. Five teaching methods were identified which might be used to transfer tolerance values. These are using a controversial issue, introducing a case study about prejudice and discrimination, reading literature, drama and visiting minority communities. The implication of this study suggests teachers should use these content knowledge and teaching methods when they teach tolerance.
\end{abstract}

Keywords-citizenship education; teaching tolerance; content knowledge; teaching methods

\section{INTRODUCTION}

The importance of teaching tolerance has been seen in schools, especially by teachers delivering social studies. Learning in the classroom contributes to students learning directly by delivering knowledge theoretically. The classroom in schools is also an environment where students attend every day, and they learn and practice how to act tolerant from their teachers. In England, teaching tolerance values is part of citizenship education because this module educates students in moral and social responsibility [1] and global studies [2]. The teacher can help students understand, and encourage them not to discriminate towards their friends who differ from them Also, the teacher can ask students not to be prejudice due to a single-world view before they know more about the particular issue. Therefore, teaching tolerance educates pupils and equips them with skills, knowledge and a positive attitude which is necessary for social interaction.

More specifically, tolerance is defined as people who are patient with different situations and people or people who can endure something they dislike. Tolerance also means creates people to have respect and recognition [3]. Teaching tolerance also deals with discrimination. The schools have a responsibility to inspire students to have a positive mind-set and not to discriminate against other people who differ from them. It is argued that the core idea of learning tolerance is how the thought translates into actions and when we are talking about respect for human rights, tolerance is about avoiding discrimination [4]. The role of the citizenship teacher in schools can perhaps change a student's attitude from a singleminded world view to be more open-minded. As such, the module can encourage students to have tolerance.

The significance of this dissertation will be revealed by considering two aspects, the content knowledge and the teaching pedagogy for teaching tolerance in schools. Content knowledge refers to teaching materials or the content which will be conveyed to students to make them understand deeply and how to apply the knowledge in daily life [5]. In addition to this, teaching religious values can also be part of the content knowledge to teach tolerance [3]. This content knowledge needs to be taught to students to make them understand the concept of tolerance. Therefore, content knowledge about tolerance within citizenship education will be the major concern in this research.

Apart from content knowledge, an appropriate pedagogy may play an important role to educate students in tolerance. Pedagogy in education deals with an appropriate method of delivering such content knowledge towards their students [6]. Teachers use a wide variety of methods and must know the most appropriate way to make their student understand tolerance. For example, there are a lot of methods that can be used to enable students to be tolerant, such as introducing the victims of intolerance, the attitude or source of intolerance, and 
basic human rights [7]. As such after learning tolerance with an interesting discussion, students should not discriminate or show prejudice towards others.

The purpose of this research is to address the issue of content knowledge and teaching method for tolerance within citizenship education in Indonesia.

\section{A. Why is Teaching Tolerance Importance?}

Students need to learn tolerance in school. This idea is supported by a wide range of research studies on tolerance and education, which revealed that educating pupils about diversity in schools could lead to tolerance [8-13]. Citizenship education provides an understanding about tolerance in schools [12]. However, this is not the only subject transforming tolerance values in schools, because global education also has the goal to make students become more tolerant [2]. Global education teaches students how to be a global learner, who enjoys learning and values diversity [14]. However, global studies is not included in the Indonesian school curriculum. Since the participants on this study are Indonesian teachers, it will focus only on citizenship education. This section will discuss three main reasons why teaching tolerance is important in Indonesian schools.

The first reason is that Indonesia consists of a diverse population with many different ethnic and religious backgrounds [15]. There are perhaps 600 different ethnicities from Sabang to Merauke. In addition to this, Indonesia is also a diverse nation in terms of religion $[16,17]$. For example, law number 1/PNPS/1965 stated that Indonesia has six religions, which are Islam, Christian, Buddhism, Hinduism, Protestant and Confucianism [18]. However, although this country consists of six religions, Muslim people are the largest population [19]. Thus, teaching tolerance is needed in schools.

The second reason is that the diversity leads to intolerance, particularly prejudice and discrimination among minority ethnic and religious groups. In Indonesia, there are many minority ethnicities which have experienced discrimination. One of the ethnic groups, which experienced a state discrimination, is Chinese Muslims, and it has happened over the past three decades [20]. They became stateless citizens because they are identified as a communist group and aligned to the Beijing government. In Indonesia, the communist party is banned by the government because the party does not fit with the basic Indonesian constitution. Although the government has enacted a new Bill, number 12/2006, about citizenship status, this matter has continued and has not been resolved.

In addition to these two reasons, recently there was a dispute among Muslim and Chinese Christians in Indonesia after the Jakarta Governor was guilty of Blasphemy. The former governor called Basuki Tjahaja Purnama, a Chinese Christian, was found guilty because he misinterpreted Qur'an verses (Muslim holy book) and it made the majority of Muslim people in Indonesia angry [21-23]. This dispute led to a huge demonstration in Jakarta, including students in schools. Although Ahok has an excellent leadership experience to lead Jakarta, the majority do not want to elect him to be the leader because he is a Chinese Christian [24]. As a result, Muslims and Chinese Christians are in conflict and it is happening in school as well.

On the other hand, there is some critiques who against teaching tolerance. Gray has argue that teaching tolerance can create something which is undesirable things are tolerated [8]. For example, when most people against LGBT (lesbian, gay, bisexual, and transgender) community, teaching tolerance to some extent promotes that this group of people should be tolerated. In one school, teacher encourage students to discuss about LGBT community and encourage them to get an approval about these groups [25]. As such, this can create a conflict between people who agree and disagree to make LGBT equal.

\section{B. Review of Education for Tolerance in Indonesia}

After considering why teaching tolerance is important in Indonesia, it is interesting to see how the Indonesian education system deals with the issue of tolerance in schools. There are a number of modules and a variety of ways that the school system addresses the issue of tolerance. This part will briefly discuss two school subjects, which are religious education and citizenship education that include tolerance value and will review some of the Islamic schools that teach them.

To teach tolerance in schools, the government has imposed the rule that there are two subjects in schools, which contribute to teaching tolerance. This policy has been stated in the education law system number 20/2003 (Indonesia. The President of Republic of Indonesia, 2003). The first module dealing with teaching tolerance is religious class. The religious class is compulsory and it should provide all official religion teachers in schools based on what students believe in [26]. However, religion classes have not addressed the issue of religious tolerance because the aim of this module is just teaching confession, doctrine ways and heaven [3].

Alternatively, citizenship education can be used as a school subject to teach tolerance [27]. In Indonesia, "citizenship education is commonly called Pendidikan Kewarganegaraan or abbreviated to be Pkn" [28]. Based on the Indonesian education system, law number 20 in 2003, citizenship education is a school subject which can inspire people to live in harmony and peace, although they come from different backgrounds. As such, this module can be an alternative to teaching tolerance in school.

At the school level, Islamic schools have tried to address the issue of prejudice and discrimination. These Islamic boarding schools are called Pesantren. One of the schools is Darul Falah, located in Yogyakarta province, Indonesia [29]. In the classroom, apart from citizenship education, sociology, and history, this school introduced the principle of Islamic Faith and an Islamic Ethic called Aqidah/Akhlaq to teach tolerance. These subjects deal with how students interact with other people based on Islamic values. In contrast, outside the classroom environment, there is a culture in which students gather together at lunchtime. They eat food in a small group consisting of six to eight people every day. This kind of school environment encourages students to be more tolerant. However, this research is a single study which has only 
happened in Islamic school, and every educational institution has a different policy on teaching tolerance.

\section{LITERATURE REVIEW}

\section{A. Definition of Tolerance}

Tolerance has been defined in many ways by different scholars. The most common and simplest meaning of tolerance is to permit something we dislike and to bear with it [4]. This perhaps means that the attitude of tolerance is that people can endure something in the circumstances that they feel uncomfortable. Tolerance also gets defined as "having patience with a difference" [3]. This suggests that tolerance is an attitude which shows passiveness towards other people's activities which are disliked, but accepted. This is similar to Bretherton who defined tolerance as "the willingness to accept the difference" [30].

However, there are some limitations in achieving tolerance, because not all activities can be accepted and tolerated by people. Jolly claimed that some activities related to "public safety, health or morals, or protection of the fundamental rights and freedoms of others" cannot be tolerated. For example, in general, students are not allowed to bring knifes to schools, unless they will use it as permitted by teachers. Also, they are not allowed to bully their friends in schools because it causes upset and anger. As a result, not all activities can be tolerated [4].

\section{B. Conceptualisation of Tolerance}

After knowing the definition of tolerance, it is helpful to understand more about the conceptualization of tolerance. This will perhaps provide a deeper understanding about what tolerance is. Although there are a lot of concepts about tolerance, this study focuses on three concepts of tolerance. These are political tolerance, prejudice and discrimination.

Political tolerance is defined by "granting opponent certain rights" [31]. It is because freedom to express ideas is one of the characteristic of a democratic society [7]. In addition to this, granting the objectionable groups political and civil rights such as freedom of speech are also considered a political tolerance [31]. For example, although freedom of speech is important in the USA, some pupils still have the view that people affiliated to certain groups such as the communist party cannot express their idea [32]. As such, teaching tolerance is necessary in schools.

By learning political tolerance, students are expected to have certain characteristics. Firstly, they are expected to change their attitude from a single-minded world view to a broader perspective and let them explore different ideas with their friends [31]. They also stated that understanding political tolerance can also prevent students from forming extremist views towards other people who are categorized as an objectionable group.

The second conceptualization of tolerance is nondiscrimination. The tolerance is an act of nondiscrimination towards an individual or a group of people [4]. Discrimination means restricting people or a group of people from enjoying their rights as a human [33]. In reality, discrimination sometimes occurs when people are restricted in political, economic and cultural rights towards the member of an ethnic, religious, or other communal minority [34]. At school level, some students with white skin may not choose to have a discussion with those identified as black skin. Therefore, after learning tolerance, students are expected to reduce the attitude of discrimination towards other people who are minorities in schools. The tolerant students should be less disruptive or violent towards their peers, in class.

The last categorization of tolerance in this study is avoiding prejudice towards other people. Teaching tolerance means encouraging students in schools not to be prejudice without sufficient evidence. Prejudice is defined as the preconceived opinion about people or someone who is assigned as a member of a particular community which is not based on reasons, and it is often more a negative than positive opinion. Also, people having a prejudice judge negative opinion with insufficient evidence [35]. Furthermore, the most common definition of prejudice is stated by Allport who claimed that prejudice is "a hostile attitude towards a person who belongs to a group, simply because he belongs to that group, and it is therefore presumed to have the objectionable qualities ascribed to the group" [36]. From these two perspectives, a general definition can be drawn stating that tolerance means avoiding having a negative prejudice towards other people without sufficient evidence.

After understanding prejudice, students are expected to make inter-religious friendships or inter-ethnic friendships [3]. Teachers can change student's attitude to let them recognize that people who are different to them are not dangerous and reduce negative prejudice towards others [31]. In addition to this, an additional purpose of teaching tolerance is to improve literacy skills and make students recognize different perspectives on sensitive issues.

However, although these three conceptualizations about tolerance as well as the purpose of teaching tolerance seem to be possible, it is not an easy task for teachers and it takes place over a long time and school cannot do it alone. Changing student's attitude to have more tolerance is like transformative learning [37]. He argued that there are many frames of reference in every child which perhaps needs a lot of time to change their attitude. One frame of reference is habit of minds [37]. He also argued that everyone has different habits of minds which influence their attitude. Such as parents, environments, media, and others can influence their habit of minds. Therefore, changing student's attitude to have more tolerance is tricky and it needs more influence or culture to change their belief.

\section{Citizenship Education}

To begin, it is helpful to discuss some school subjects which can transform tolerance values in schools. There are a lot of subjects which can include tolerance content. Although this dissertation will focus only on citizenship education as the main study, it is aware that other school subjects such as global education and religion education also educate pupils to have tolerance. As such, this part will discuss and explore global studies, religion education, and citizenship education as an 
alternative view of teaching tolerance. Following this, some possible content knowledge which covers tolerance values will be analysed.

Global education is designed to create a global learner for the future [14]. As the world is more globalized, every citizen needs to think and act globally. One of the purposes of global education is to create a culture of tolerance. In England, the government has created a program called "developing global dimension" in schools which has two main purposes. These are appreciating the characteristic of different people everywhere, and to value diversity [2].

More specifically, global studies has four main areas of content knowledge which can contribute towards the creation of global learners who will perhaps have tolerance values. These are: to study cultures different from their own; to clarify their own value or a sense of personal identity; develop skills to combat prejudice; and discrimination [2]. This should result in students having a mindset which can contribute towards a better society $[2,38,39]$. This content knowledge can be seen as essential to transform students to be global learners who have a tolerance value. Although global studies teaches students to have tolerance, it cannot be applied in Indonesia because the school curriculum does not include global studies. Alternatively, teaching tolerance can be transformed towards religion education and citizenship education.

Religion education is an alternative to teach tolerance. The religious class teaches students how to live and have tolerance for other people who are from a different religious background to them. The content knowledge which can be taught through this school subject is discussing different religious values. Students could be given a real example of people who help each other from different religions. Although religious class can teach tolerance, there is no guidance for teachers on how to teach religious tolerance. Therefore, another subject such citizenship education can be used to teach tolerance [3].

Citizenship education is a special subject in school for educating students about society and contemporary issues. This module enables the student to be a good citizen in a community. Recent research revealed that the term "good citizens" refers to those who are concerned about their society and tolerance and they are willing to get involved in a community [38]. For example, citizenship education in Australia is taught because there are social problems. These problems can include: the breakdown of a community network; less trust and responsibility towards neighbors and institutions; anti-social behaviour; increased truancy and exclusion; and a high pregnancy level among teenagers [38]. However, creating good citizens or curing social problems can take years, shaped by some forces and experiences, including importantly, education aimed at this very goal [40]. Thus, creating a tolerant society is part of establishing a good citizen which cannot be taught instantly, it probably needs to be introduced in schools in religion education and citizenship education.

In Indonesia, citizenship education is a compulsory module from primary education to higher education because it is part of the education system. This is an alternative module of teaching tolerance in schools, because citizenship education has a lot of content knowledge contributing towards tolerance. Although there is a lot of content knowledge, at least two topics can contribute to transform tolerance value, which are human rights, and trust and responsibility.

The first content knowledge which can contribute towards tolerance value is human rights [40]. Leung has argued that as the world is like a global village where people are interconnected, they need to understand clearly about human rights [41]. One of the rights which is owned by every person is freedom of speech as a basic human right. This right allows people to freely express their idea and opinion in public, regardless of their gender, race, ethnicity and political affiliation [7]. If students learn freedom of speech in school and allow their friends to express their ideas, they will have learned tolerance values. As such, learning human rights as part of citizenship education can be important to help students have more tolerance.

The second content knowledge is trust and responsibility towards people. This is part of social and moral responsibility [1]. The aim of this concept of citizenship education is to create a good citizen. In addition to this, Davies, Gregory, and Rileey have argued that good citizens have a characteristic, which is a social concern characteristic [42]. They need to let other people or their friends have a different view to them. As such, this type of citizenship education focuses on creating a good citizen which has the character of trust and responsibility towards other people.

\section{Teaching Tolerance}

Teaching method is another important aspect of this study because it will be used as a way of transforming tolerance values toward pupils. The relationship between teacher and pupils is crucial because teacher needs to know the attitude of their students [36]. As such, a teacher can determine which one of many appropriate methods to use to teach tolerance. This section will discuss several teaching methods which can be used as tools for teaching tolerance.

There are a lot of research studies about teaching tolerance across the world and they introduce a variety of pedagogical approaches and content knowledge for tolerance, [31,36,4346]. However, although these studies address the issue of teaching tolerance in schools, the studies have not discussed how teaching tolerance is taught within citizenship education. They tried to reveal that teaching tolerance is better to be taught through another subject such as history, social studies, geography and school life. This study will focus on only ten teaching methods which are adopted from these experts, then perceptions of Indonesian citizenship education teachers are asked about their methods.

The first method for teaching tolerance is using dramatization or role play. This method provides students with a situation in which prejudice and discrimination are presented and played on the stage. He also stated that students can play a role as a minority group who experience discrimination and violence in society, and they will feel how people in that community live. However, although some experts argue that using dramatization can transform tolerance values, it is inevitable that changing attitude cannot be done directly. Some students face difficulties when they are required to have 
empathy when performing drama in class. As such another method which can bring students closer to the real-life experience will be suggested [47].

The second teaching is a field trip to a minority community or experiential learning. Cross has argued that taking students to a minority community allows them to interact and communicate with indigenous people who are different from them, so that they maximize their learning outside the classroom [48]. Visiting a minority community has at least two main benefits for their students. Firstly, students can learn by sharing, dialogue, talking, discussing and watching what the local community does relating to the way of life [49]. Also, both students and teachers can utilize the life experience outside of the classroom [50,51]. Therefore, after visiting the community, students will perhaps have different positive feedback and perspective regarding people who are different from them. However, experiential learning cost a lot of money for travelling to visit some particular places, which might be the drawback of this teaching method.

The third teaching method is using history-based lessons. This is a teaching method in which teachers tell students a story relating to prejudice and discrimination. Demircioglu has argued that there are at least three main benefits from using story based lessons: a story makes learning interesting; enjoyable; and students can recognize that people living in different religious and ethnic communities can live peacefully together [52]. However, although this method seems to be appropriate to teach tolerance, it needs a lot of preparation by the teacher, especially finding an interesting story that the students can connect with, otherwise students will become bored.

Apart from these three teaching methods used to teach tolerance addressing prejudice and discrimination, there are other pedagogical approaches which might be appropriate to teach students about prejudice and discrimination. These methods are: conflict resolution [53], reading literature [44], introducing a case study about intolerance [7]; encouraging students to join volunteer activities or take social actions [54]; introducing a case study about prejudice or discrimination and using controversial issues [7]; and using small group discussion. The teaching methods mentioned above might not be appropriate for some teachers because of different students' characteristics, learning time and school resources. However, the results of this study might suggest other teaching methods based on the participant's experiences.

\section{METHOD}

The methodology chapter provides the research design to address the research questions. It provides detailed information not only on how to conduct the research, but also the limitations and difficulties when carrying out the research. Thus, this chapter will be divided into six-sub chapters, which are research questions, research design and data analysis, participants and sampling technique, ethical issues and data collection, and limitation on research methodology.

\section{A. Research Question}

This study has two main research questions which are:
- What are the teacher's perceptions about the content knowledge used for teaching tolerance within citizenship education?

- What are the teacher's perceptions regarding the method that addresses prejudice and discrimination regarding race and religion?"

In order to get the specific aims, these two research questions have five subsidiary questions, which are:

- What do teachers perceive is the main purpose of teaching tolerance in citizenship education?

- What are the contents of citizenship education contributing to teaching tolerance?

- Why the contents bring about tolerance?

- What are the teaching methods that teacher use in citizenship education that contribute to tolerance?

- Why do teachers use these teaching methods that addresses prejudice and discrimination regarding race and religion?

\section{B. Research Design and Data Analysis}

This dissertation used a mixed method by combining quantitative and qualitative research approaches. There are two reasons why a mixed method is suitable to answer the research questions. Firstly, the quantitative method makes this study easy and quick, and can get information for many participants with an online questionnaire. Also, the data analysis is probably less time consuming because it is helped by statistical software analysis called SPSS. However, the quantitative method makes it more difficult to ask the reason why teachers are using these teaching methods. As such, the qualitative approach using interviews can address these matters, because it can provide in-depth and rich information about participant's views and can provide more detailed information, but this method is based on small and nonrandom sampling [55].

The combining of both quantitative and qualitative research approach can gain more strength and reliable results [56], and this mixed method can also help the researcher to obtain full and complete data about a teacher's experience [57]. Therefore, a mixed method can answer not only the teachers' perception from online questionnaires, but also the reasons why teachers use particular teaching methods to teach tolerance, which address prejudice and discrimination.

Descriptive statistics, frequency distribution and cross tabulation were used to analyses and present the data quantitatively. Mujis has argued that bivariate analysis between nominal variables (gender, level of school, religion, ethnic background) and ordinal variables (the purpose of teaching tolerance, content knowledge and teaching methods) are suitable to use cross tabulation, then the chi square test will be presented [58]. The chi square was used to see whether there is a different response or not from the nominal variable towards the ordinal variables. This analysis also used SPSS because this software makes it less time consuming [55]. 
In addition to data analysis, content analysis was used to analyse the interview. The interview text was transcribed by following three ways such as, open coding, axial coding and selective coding were used to categories the teachers' perceptions regarding three research questions by using nVivo [59]. The interview was used for citizenship teachers to understand the reasons why such content knowledge is suitable to teach tolerance and what teaching methods are appropriate to be used.

\section{Participants and Sampling Technique}

The participants in this research were citizenship education teachers in Indonesia. There are three main reasons why Indonesia is selected to carry out this study. Firstly, Indonesia has a citizenship education module and this is compulsory from primary level to university level (President of Republic of Indonesia, 2003). Secondly, some schools have a culture of tolerance which is interesting to see what is happened in the classroom when citizenship teachers educate in tolerance [3]. Also, Indonesia is a diverse country which has different ethnic and religious backgrounds as well as cultural diversity. As such, this study will focus only on citizenship education teachers in Indonesia.

The participants were selected via snowball sampling for an online web-based questionnaire and convenience sampling technique for the telephone interviews. The Snowball sampling started by identify several teachers who have experience teaching citizenship education in junior high school and senior high school to answer an online questionnaire, then they were asked to forward the questionnaire to other teachers who have similar characteristics $[59,60]$. This method makes easy to get a lot of participants because the questionnaire can be shared to social media of citizenship teachers. In addition to this, convenience sampling was used to interview the teachers. This technique is referred as an accidental or availability sample [60]. The researcher identified several Indonesian citizenship teachers who were suitable to participate in this research.

\section{Ethical Issues}

Ethics plays an important role in conducting research. The ethical issues in this dissertation address the issue of informed consent, privacy, anonymity and confidentiality, and freedom to withdraw $[55,61,62]$.

After gaining ethical approval from the ethics committee in the department of education, the University of York, the next stage was giving the participants the consent form. Kellett has argued that the consent form contains some information about the activities that will be taken by participants [61]. This dissertation showed the participants that they will be asked about their experience of teaching tolerance, personal identity, the purpose of teaching tolerance, content knowledge and teaching methods. In addition to this, the participants have been informed that their name will not be asked on the questionnaire and their record will be put on the protected laptop in which the password is only known by the researcher. Also, their names will be changed to pseudonyms so that they will not be identified. Although their identifiable data will be kept for three months, the written record will be saved for ten years. The participants also were informed where this research will be published. In addition, the last ethical consideration addressed in this dissertation is the freedom of withdrawal. Therefore, this research was conscious of ensuring that no harm was caused to the participants and it has met all the requirements of the ethics committee.

\section{E. Data Collection}

1) Pilot survey and interview

A pilot survey is crucial for the research because it brings about a wide range of opportunities for the results of the findings. There are three main benefits from the pilot survey and interview in this dissertation. Firstly, "it checks the clarity of the questionnaire items, instruction and layout" [59]. In addition to this, it provides feedback about the validity and readability by the reader, so that some difficulties and ambiguities in the words can be eliminated. Lastly, it also checks whether the questions are too easy or too difficult for the participants. This dissertation has addressed the pilot survey and pilot interview.

The pilot survey was carried out in advance by sending ten online questionnaires. Two people were citizenship education teachers in Indonesia while the others are master students in the University of York. Seven online questionnaires were returned with a lot of feedback. The majority of feedback for the questionnaire was about the readability of the contents, some misspelt words, and improvement of formal words. The results show that there is some changes and improvements spelling, making the questions easier to read, and reducing some open questions. Then, some vocabulary was changed to be more appropriate and formal Indonesian words.

The pilot interview was also carried out before the formal research. An Indonesian citizenship education teacher participated in an online interview. The time, internet connection, questions and the difficulty of questions were addressed. As a result, there was a change from a video call to a voice call using Whatsapp application because this application works much better a than video call. Also, there were some changes making the interview questions easier. The findings of the pilots were not analysed and they were also not included in this research [63].

\section{2) Questionnaire}

This study used a web-based online questionnaire, called Qualtrics, to answer the research questions. There are three main reasons why an internet-based survey was used to carry out this study. Firstly, this online questionnaire can "gather data on a-short basis and hence it is economical and efficient study" [59]. Also, online questionnaires using Qualtrics has the benefit of getting a considerable number of participants because it is easy to reach people [64]. In addition, the teacher as a respondent can fill the online questionnaire in at home or even on holiday so that it is easier and more efficient [65]. Although an e-mail based survey is also useful as an alternative, this is assumed to be more difficult because participants need to print and send it back to the researcher. Therefore, this dissertation focussed on only using a web-based questionnaire. 
The questionnaire consists of 45 overall questions. The background questions used to collect the data are eight questions which are about level of their schools (junior

high school and senior high school), type of school (public or private school), gender, ethnicity and religious background, length of teaching, teacher training specialist background, and the module that they taught in school. Twenty Likert-type questions on a scale 1-5 to identify the perceptions of the teachers regarding the purpose and the content knowledge of teaching tolerance in schools ranging from strongly agree, to strongly disagree. Ten questions are about the teaching methods that can be used by citizenship education teacher and it has seven options about their experience whether it is effective or not to teach tolerance. Additionally, four open ended questions asking about other comments regarding teaching tolerance which are not mentioned in the list of questions. Two other questions asked their email or contact number and whether they were willing to be interviewed and willing to receive a soft-file copy of the dissertation. All questions used Indonesian language to make it easier for them to understand the questions, because all the participants were Indonesian teachers.

\section{3) Telephone interview}

In order to gain an in-depth understanding about the study, telephone interviews were used to get rich data. There are two main reasons why telephone interviews were used to carry out this study. The responses from interviewees can clarify the queries regarding the teacher's perception of the purpose, content knowledge and teaching method of tolerance. Also, the telephone interview can reduce cost in time and travel to reach the participants. As such, this method was suitable for this research [59].

In addition to this, there are three main questions which participants were asked, the purpose of teaching tolerance, the content knowledge and some appropriate teaching method to educate students more in tolerance. These three questions were explored based on teacher experience. Also, the language used for the interview is Bahasa Indonesia, because it makes participants understand more and feel more comfortable.

\section{4) Limitation}

This section is a reflection on the limitations. There are three major limitations which will be described in this section and could have threatened the validity and reliability of this study.

The issue of sampling technique is important in research. Admittedly, this research used nonprobability sampling such as snowball sampling for the online questionnaire and convenience sampling for the telephone interviews. Snowball sampling and convenience sampling techniques cannot control any representativeness and the parameter of generalizability in this sampling are neglected [59]. This is true because there are a lot of citizenship education teachers in Indonesia and not all teachers had an equal chance to participate in this research. Therefore, it threatens the external validity, particularly on the issue of generalizability.

In addition to this, the online questionnaire using Qualtrics faced some problems. There were a lot of people who could not complete the questionnaire, only 103 out of 252 participants completed this online questionnaire. Some participants may not tell the truth because it can be seen from the answers in which they choose strongly agree for all Likert-scale questions. This problem may be caused by the slow internet connection or they are unfamiliar with Qualtrics.

The telephone interview also had some problems. Since this interview used Whatsapp application, some participants may not have this application so that they cannot take part in this study. Also, due to the poor internet connection, some voices were unclear to hear when transcribing the interview text. As a result, it may have caused a bias because of misinterpreting transcribing data.

All, it is suggested that for the further study regarding tolerance, simple random sampling might be appropriate to collect data from online questionnaire. Also, face-to-face interview is recommended to gain a full attention from participants.

\section{RESUlt AND DISCUSSION}

\section{A. Summary of Key Findings}

The findings from this study suggest that there are three main purposes for teaching tolerance. These are to prevent disruptive or violent behaviour in class, to reduce discrimination among students who are from different ethnic and religious backgrounds and to let students make interreligious and inter-ethnic friendships. As such, the content knowledge to achieve these goals is mostly discussing human rights, a sense of personal identity and a sense of community involvement. In addition to this, four teaching methods can be used to teach tolerance addressing prejudice and discrimination. The teaching methods based on Indonesian citizenship teacher perception are using a controversial issue, introducing a case study about prejudice and discrimination, reading literature and using drama or role play. More details about the key findings and some comparisons with the previous literature in the past will be discussed in this chapter.

\section{B. The Purpose of Teaching Tolerance}

The first purpose of teaching tolerance is to let students have inter-religious friendships and inter-ethnic friendships. Based on the majority of teacher's opinions, there are three main reasons why encouraging students to make inter-religious friendships and interethnic friendships is important. Indonesia is a country which has diverse religious and ethnic backgrounds, such as Muslim, Catholic, Protestant, Hinduism, Buddhism, and Confucianism. The second reason is that because there are some parents who restrict or ban students making friends with those who are from different religious backgrounds, some teachers tried to change student's mind-set. As such, encouraging students to make friends with those who are different ethnic and religious background is important.

The finding is similar with two other research studies about tolerance which revealed that making interreligious and interethnic friendship is important [3]. However, the way to encourage students to mix their culture is different. 
There are two ways of encouraging students to mix culture among students. These are creating a food festival on the celebration of religious ceremonies and creating an event to pray together [3]. These two activities are an effective way to make students mix their culture. In contrast, there are different ways to create an inter-religious and interethnic friendship in England. In the classroom, "teachers discuss different issues related to the student's lives in and out the classroom. Teachers had also organised similar activities for the playground that allowed teachers to interact and work with students outside regular class time".

The third reasons why encouraging students to mix cultural friendships is important is that living in a diverse place drives to conflicts between groups. In Indonesian, there are some conflicts which create Indonesian high school students to break down their relationship with their friends who are different to them, particularly religiously different. A participant said that due to the election of Jakarta Governor, in which one of the candidates was Muslim and another was Chinese Christian, it influenced student's opinion in the participant's school not to make friends with people who are different to them. However, these opinions come from several teachers who teach in schools located in Jakarta. This might not apply for other teachers in rural areas.

The way teachers encourage students to make friends is that they give some proverb from one Indonesian President, Gusdur, who said that if you give all kindness to all people, they will never ask your religion. Although this is one of the ways for students to make friends with those who are from a different background. Another way to make students understand diversity and make inter-ethnic and inter-religious friendship is by showing a movie. One of the participants said that the movie called "tanda tanya" or in English it is question tag, could be one effective way to encourage students to make friends with others, because this movie shows them how diverse Indonesia is. Thus, it is one of the stimulus for them to have a lot of friends.

On the other hand, the way the teacher encourages students to make friends by giving proverbs and showing movies is different to the work of Mezirow on the theory of transformative learning. He said that people can change their habits of mind by critically engaging in problem solving, reading books, communicative learning and hearing a point of view [37]. As such, teachers should make more effort to create student engagement in their learning with problem solving activities.

Another Interesting purpose of teaching tolerance is that students are encouraged to change their attitude from singleworld minded view to broaden their view or open-minded. Godwin, Ausbrooks, and Martinez have argued one of the aims for teaching tolerance is to let students become open-minded [31]. Similarly, this study has been confirmed by a lot of school teachers who argued that students are encouraged to be openminded by having a lot of ideas and respect other peoples' perspective. For example, most teachers argue that discussion in classrooms can encourage students to have different opinions from their friends. Then, some of the students might become open minded. However, this is only the opinion of one teacher and it is difficult to generalize the results.

\section{The Content Knowledge for Teaching Tolerance}

This part presents the discussion about the content knowledge which can be used to achieve the purpose of teaching tolerance. Although there are a lot of content knowledge about tolerance within citizenship education, human rights can contain many tolerance value lessons in junior high school and senior high school. This part will be divided into two main reasons, which are from junior high school teachers and senior high school teachers.

In the junior high school, the findings suggest that there are two main reasons why tolerance value can be taught within human rights. Firstly, teachers always encourage students to respect rights and responsibility towards other people, and secondly, respecting rights and responsibility towards the country. For example, students are encouraged to learn freedom of speech and conveying a public opinion. As such, after learning this content knowledge, students are expected to have a broad idea and be open minded.

The findings of teaching human rights in junior high school is slightly different with the work of Al-Zyoud, Brown, and Morgan in 2013. Although both research studies suggest that human rights can contribute to tolerance and diversity, the content knowledge is slightly different. They argue that students can learn basic human rights such as right to live, travel and express views and ideas. A significant difference between junior high school in England and Indonesia, is that students learn rights to live and travel in England, while in Indonesia students focus on freedom of speech.

Interestingly, the content knowledge in senior high school is also different from junior school level. In this level, teachers argue that there are three main goals for students after learning human rights. Students learn freedom of religion, nondiscrimination and freedom of speech. Since freedom of religion is emphasised in senior school level, students are expected to understand that they live in a diverse content.

Compared to the results from Avery, Sullivan and Wood, their studies also reveal that learning human rights supports students to have tolerance values in school. Although the findings support Avery, they do not provide the detail of the kind of rights that students need to learn in school. They just suggest that students need to learn human rights in general, rather than as specific knowledge [7].

In addition to this, the findings are different to the work of Leung [41]. They focused on studying human rights in Hongkong, and the results focused on self and personal development. In Hong Kong, students are encouraged to understand oneself and the challenge and opportunities a person has during adolescent, while this dissertation encourages students to learn other peoples' rights such as freedom of religion and freedom of speech. However, both studies support learning human rights in order to make students understand tolerance values.

Although there are eight statements about content knowledge for teaching tolerance, human rights is perhaps 
considered as appropriate content knowledge for teaching tolerance. The implication from the discussion suggests that tolerance value can be transformed from learning human rights either in junior high school or in senior high school. The overall result agrees with the literature that human rights is part of citizenship which can change a students' mindset, although some content of rights are slightly different.

\section{The Teaching Method for Tolerance}

This part presents a discussion about the teaching method for tolerance addressing the issue of prejudice and discrimination. Although there are a lot of teaching methods which can be used as a way of transforming tolerance values, this discussion part will present using drama and visiting minority communities because these two methods are the most favoured way of teaching among citizenship teachers.

The majority of Indonesian citizenship teachers who were interviewed argued that using drama is one of their favourite ways to convey tolerance values. There are four main reasons why drama is appropriate to be used. Teachers argue that students not only learn the theory, but also experience a role play, so that they can experience a real-life scenario. Also, students can change their attitude to be more positive towards other people who are different. However, due to the time restrictions, most teachers ask students to create a video rather than presenting in the class.

The benefit of using drama has similar results. He said that by participating in role playing, prejudice and discrimination can be presented and performed by students, so that students can feel when they are discriminated against by other people. Another finding also confirmed that dramatization can allow students to see directly prejudice among children [36]. As such, this method can be used as an option to teach tolerance values [47].

On the other hand, although this method seems to be an effective way, the drawbacks cannot be avoided. At least, the findings suggest that there are two major drawbacks which most teachers experience when they ask students to perform drama. These are too much academic workload for pupils and some students just play drama for fun, and they do not engage fully in the discussion. However, the drawbacks are different from the results by McGregor who stated that students found it difficult when they are required to show sympathy and it can create a negative image for a minority community. The most important things highlighted on the drama or role playing is that it cannot guarantee that students can change their attitude to have more tolerance after acting, because it is not the only way of changing attitude [47].

Another teaching method which is a favourite among teachers is visiting a minority community or it can be called experiential learning. Most teachers argue that visiting a minority community can create a better understanding to experience the real life of other people who are different from the students. For example, one of the interview participants said that visiting Kasih hills located in Manado can make students understand that Indonesia is a diverse country in terms of religion, race and culture.
These benefits are supported by literature about the advantages of experiential learning for understanding tolerance value [50]. There are three main benefits which students might have when they experience outdoor activities. Firstly, students are more likely to remember the activity that they learn when they visit a community. Also, some students will find it worthwhile when they collect the data in the real world. More importantly, it will be beneficial when they apply the knowledge in their real life. However, apart from these benefits, there are also drawbacks from this experiential learning which might be faced by teachers.

There are two main drawbacks, from teacher opinion, in conducting experiential learning of visiting a minority community. They said that this learning activity will cost a lot of money so that school or students need to pay the cost for traveling and accommodation in the community. This problem might be difficult for school in where the majority come from low-economic income. Secondly, some teachers find it difficult to obtain the permission from their head teacher. Although it is a good learning activity, some school principals might disagree with this activity. In addition to teacher opinion, some problems might be faced such as the students might worry about spending days out of the school. Students might be afraid of the changing weather, insects and animals.

\section{E. Implication and Suggestions}

These findings have an implication for Indonesian citizenship teachers. The results regarding content knowledge and teaching method can be suggested for those who are willing to teach tolerance in schools. Teachers can use these five varieties of teaching methods when they transform tolerance values. Although the participants are Indonesian citizenship education teachers, it might be worthwhile for other teachers who live in diverse nations to implement these methods.

Further research could be improved if the research time was more than three months, so that they have sufficient time to reach a wider sample. It is suggested that it will be better to focus investigating a specific method such as drama, visiting small community or small group discussion. By using observation in the classroom directly, the finding will perhaps be more reliable and applicable for teachers. Also, it is interesting to see the school policy or school culture on how to create tolerance among students because it is argued that teaching in the classroom cannot give a significant result towards changing students' attitudes.

To obtain rich data, and more in depth-interviews, face toface interviews might be better to conduct a similar study. This is because based on the experience of this research, it cannot obtain thorough data because due to the internet connection some participants found it difficult to explain their reasons more. By using faceto-face interviews, there might not be distractions when participants are interviewed.

\section{CONCLUSIONS}

This chapter provides a summary of the key findings about teaching tolerance within citizenship education in Indonesia. As seen in the methodology chapter, the research questions for 
this study are to know the citizenship education's teacher perception about the purpose or the aim of teaching tolerance, the content knowledge of teaching tolerance, and some pedagogical approach which might be considered the most effective to teach tolerance. Although the researcher has tried to provide the best results, some limitations cannot be avoided. Therefore, the concluding chapter will show some key findings as well as some limitations and restrictions during the research. It will also give suggestions to undertake further research in this field.

The first research question was to identify the teacher's perception about the purpose of teaching tolerance. This study has revealed that in terms of Indonesian citizenship education teacher opinion, they argue that there are three main purpose of teaching tolerance. Making inter-religious friendship and interethnic friendship are the main aim of teaching tolerance. Two other purpose of teaching tolerance are to prevent disruptive behaviour in class, and to reduce discrimination among students who are from different ethnic and religious backgrounds.

The second research question was to identify the teachers' opinion about the content knowledge for teaching tolerance. There are three main content knowledge which might be considered to have tolerance values. The majority of teachers stated that human rights is probably considered as appropriate content to teach tolerance. In human rights, students in junior high school are encouraged to respect other peoples' rights and responsibility such as freedom of giving opinion in a public, while teachers in senior high school also encouraged their students to learn about freedom of religion. Two other content knowledge are, teaching a sense of personal identity and a sense of community involvement.

The last research question was about teaching method addressing prejudice and discrimination. There are five methods which might be used by a teacher to teach tolerance to their students. First of all, the teacher can use drama or role play to teach tolerance. In this method, students can probably not only understand their theory, but they can experience the feeling when they face discrimination in the drama. However, this method is perhaps time consuming. The second teaching method which can be used as an alternative is visiting a minority community or experiential learning. The real-life experience to interact with indigenous people is such priceless knowledge for their students because they can ask how people feel, exchange cultures, and enjoy the day out of the school. Although this method to visit some small community seems suitable, some schools cannot allow students to go there because of administration procedures. The other teaching methods that can be used to teach tolerance are using a controversial issue, reading literature and introducing a case study about prejudice and discrimination.

This study has some implications for teachers who teach tolerance. These five teaching methods are suggested to be used by other teachers who transform tolerance values towards their pupils. Although the research design cannot be generalized due to the sampling technique, it is worthwhile to be tested by teachers. Further research instrument might be better to focus on in-depth interviews by qualitative analysis, because it could gain a deeper understanding about the reasons why teachers use a particular method.

Where possible, further research about teaching tolerance should be conducted. The researcher suggests that the further researcher can focus on one teaching method about tolerance and use the observation method to see the real-life experience in the classroom. Secondly, since classroom activity arguably does not do enough to teach tolerance, school culture and school policy on how to create a tolerance rich environment in an educational setting might be best to carry out. Further research might find a new interesting and useful teaching method for tolerance in schools.

\section{REFERENCES}

[1] B. Crick, Essays on citizenship, Bloomsbury Publishing, 2000.

[2] A. Standish, "What is global education and where is it taking us?", Curriculum Journal, vol. 25, no. 2, pp. 166-186, 2014.

[3] R. Raihani, "Creating a culture of religious tolerance in an Indonesian school", South East Asia Research, vol. 22, no. 4, pp. 541-560, 2014.

[4] A. Jolly, Tolerance: Implications for educators, in A. Osler, $\mathrm{H}$. Rathenow, and H. Starkey, Teaching for citizenship in Europe, Trentham Books Limited, 1955.

[5] E.L. Janssen, and J.R. Erickson, "Preservice teachers' content knowledge and selfefficacy for teaching reading", Literacy Research and Instruction, vol. 52, no. 03, pp. 204-209, 2013.

[6] C. Watkins, and P. Mortimore, Pedagogy: What do we know, In P. Mortimore, Understanding pedagogy and its impact on learning, pp.119, 1999.

[7] P. Avery, G. Sullivian, and S.L. Wood, "Teaching for tolerance of diverse beliefs", theory into Practice, vol. 36, no.1, pp. 32-38, 1997.

[8] E. Gray, Teaching and tolerance: aversive and divisive pedagogical encounters, Discourse: Studies in the Cultural Politics of Education, 2016.

[9] R.J. Royce, "Pluralism, tolérance and moral education", Journal of Moral Education, vol. 11, no. 3, pp.173-180, 1982.

[10] O.H. Hansen, "Teaching tolerance in public education: organizing the exposure to religious and life-stance diversity", Religion \& Education, vol. 38, no. 2, pp.111-127, 2011.

[11] S. Grover, "Children's right to be educated for tolerance: minority rights and inclusion", Education and the Law, vol. 19, no.1, pp.59-70, 2007.

[12] F. Willems, E. Denessen, C. Hermans, and P. Vermeer, "Citizenship education in religious schools: An analysis of tolerance in Catholic schools from a virtue ethical point of view", Journal of Beliefs \& Values, vol. 31, no.2, pp.215-229, 2010.

[13] N.G. Noorderhaven, and L.C. Halman, "Does intercultural education lead to more cultural homogeneity and tolerance?", Intercultural Education, vol. 14, no. 1, pp.67-76, 2003.

[14] A. Standish, The false promise of global learning: Why education needs boundaries, USA: Bloomsbury Publishing USA, 2012.

[15] A.M. Buttenheim, and J. Nobles, "Ethnic diversity, traditional norms, and marriage", population studies, vol. 63, no. 3, pp.277-294, 2009.

[16] D. Sofjan, "Religious diversity and politico-religious intolerance in Indonesia and Malaysia", The Review of Faith \& International Affairs, vol. 14, no. 4, pp.53-64, 2016.

[17] C.Y. Hoon, "Putting religion into multiculturalism: conceptualising religious multiculturalism in Indonesia”, Asian Studies Review, pp.1-18, 2007.

[18] N. Jones, "Rediscovering Pancasila: Religion in Indonesia's public square", The Brandywine Review of Faith \& International Affairs, vol. 3, no. 1, 2230, 2015.

[19] A. Muzakki, "Ethnic Chinese Muslims in Indonesia: An unfinished antidiscrimination project", Journal of Muslim Minority Affairs, vol. 30, no. $1, \mathrm{pp} .81-96,2010$ 
[20] L. Fitriyah, Indonesian Muslim religious arrogance, Retrieved from http://www.thejakartapost.com/academia/2016/10/15/indonesianmuslims-religiousarrogance.html, 2016.

[21] C.A. Wijaya, Ahok guilty of blasphemy, sentenced to two years, retrieved from http://www.thejakartapost.com/news/2017/05/09/ahokguilty-of-blasphemy-sentenced-to-twoyears.html, accesed 23 August 2017.

[22] A. Khanif, Blaspheming religion vs blaspheming humanity, retrieved from http://www.thejakartapost.com/academia/2016/12/23/blasphemingreligion-vs-blaspheminghumanity.html, Accesed 23 August 2017.

[23] M. Hatherell, and A. Welsh, "Rebel with a Cause: Ahok and Charismatic", Asian Studies Review, vol. 41, no. 2, pp.174-190, 2017.

[24] R.J. Colesante, and D.A. Biggs, "Teaching about tolerance with stories and arguments", Journal of Moral Education, vol. 28, no.2, pp.185-199, 1999.

[25] Raihani, "A whole-school approach: A proposal for education for tolerance in Indonesia", School Field, vol. 9, no. 1, pp.23-39, 2011.

[26] C.Y. Hoon, "Multicultural citizenship education in Indonesia: The case of a Chinese Christian school", Journal of Southeast Asian Studies, vol. 44, no. 3, pp.490-510, 2013

[27] E.S. Nurdin, "The policies on civic education in developing national character in Indonesia", International Education Studies, vol. 8, no. 8, 199, 2015.

[28] Raihani, "Report on multicultural education in pesantren", A Journal of Comparative and International Education, vol. 42, no. 4, 585-605, 2012.

[29] L. Bretherton, "Tolerance, education and hospitality: a theological proposal", Studies in Christian Ethics, vol. 17, no. 1, pp.80-103, 2004.

[30] G. Godwin, G. Godwin, and M. Martinez, "Teaching tolerance in public and private schools", Phi Delta Kappan, vol. 82, no. 7, pp.542-546, 2001

[31] P.G. Avery, K. Bird, S. Johnstone, J.L. Sullivan, and K. Thalhammer, Exploring political, 1992.

[32] A. Girli, H.Y. Sarı, G. Kırkım, and S. Narin, "University students' attitudes towards disability and their views on discrimination", International Journal of Developmental Disabilities, vol. 66, no. 2, 98107, 2016.

[33] Y. Akbaba, "Who discriminates more? comparing religious discrimination in western democracies, Asia and the middle east", Civil Wars, vol. 11, no. 3, 321358, 2009.

[34] S.J. Spong, "The challenge of prejudice: counsellors' talk about challenging clients' prejudices", British Journal of Guidance \& Counselling, vol. 40, no. 2, pp.113-125, 2012.

[35] P. Leach, "Teaching tolerance", International Review of Education, vol. 10, no. 2, 190-204, 1964.

[36] J. Mezirow, "Transformative learning: theory to practice", New Directions for Adult and Continuing Education, vol. 4, pp.5-12, 1997.

[37] J. Arthur, and D. Wright, Teaching citizenship in the secondary school, Routledge, 2013.

[38] J. Annette, Education for community involvement and as service learning. In T. Breslin, \& B. Dufour, Developing Citizens: a comprehensive introduction to effective citizenship education in the secondary school (Vol. 17, p. 32). CSCS JOURNAL, J. (2006).

[39] L.F. Darling, "The essential moral dimensions of citizenship education: what should we teach?", The Journal of Educational Thought (JET)/Revue de la Pensée Educative, pp.229-247, 2002.

[40] M.S. Al-Zyound, E.J. Brown, and W.J. Morgan, "Peace education in English and Jordanian schools: a comparative study", Education Research and Perspective: An International Journal, vol. 40, pp. 211 $235,2013$.

[41] Y.W. Leung, “An 'action poor' human rights education: a critical review of the development of human rights education in the context of civic education in Hong Kong", Intercultural Education, vol. 19, no. 3, pp. 231-242, 2008.
[42] I. Davies, I. Gregory, and S. Riley, Good citizenship and educational provision, Routledge, 2002.

[43] M.I. Farisi, "Bhinneka Tunggal Ika, Unity in Diversity: From dynastic policy to classroom practice", Journal of Social Science Education, vol. 13, no. 1, pp. 46-61, 2014.

[44] R.M. Weeks, "Teaching tolerance through literature", The English Journal, vol. 35, no. 8, pp. 425-432, 1946.

[45] D.D. Latess, and R.L. Walker, "Using the adventure model to teach about diversity and tolerance", Strategies, vol. 24, no. 3, pp. 29-32, 2011

[46] E.A. Naumenko, and O.N. Naumenko, "Pedagogical experience on formation of tolerant and multicultural consciousness of students", European Journal of Contemporary Education, vol. 17, no. 3, pp. 335343, 2016.

[47] J. McGregor, "Effectiveness of role playing and antiracist teaching in reducing student prejudice", The Journal of Educational Research, vol. 86, no. 4, $215226,1993$.

[48] K.P. Cross, "Why learning communities? why now", About campus, vol. 3, no. 3, pp.4-11, 1998.

[49] E. Skop, "Creating field trip-based learning communities", Journal of Geography, vol. 107, no. 6, 230-235, 2009.

[50] T. Tapps, T. Passmore, D. Lindenmeier, and W. Kensinger, "High school physical education students and experiential learning in the community: a classroom assignment", Strategies, vol. 27, no. 1, pp. 9 12, 2014.

[51] K. Patel, "Teaching and learning in the tropics: an epistemic exploration of "the field" in a development studies field trip", Journal of Geography in Higher Education, vol. 39, no. 4, pp. 584-594, 2015.

[52] I.D. Demircioglu, "Using historical stories to teach tolerance: the experiences of Turkish eighthgrade students", The Social Studies, vol. 99 , no. 3, 105110, 2008

[53] L. Davies, "Conflict resolution, In D. Hicks, \& C. Holden, From Dynastic Policy to Classroom Practice (pp. 46-61)", Journal of Social Science Education, 2007.

[54] S. Mellor, and W. Prior, "Promoting social tolerance and cohesion in the Solomon Islands and Vanuatu In W. O. Lee, D. L. Grossman, K. J. Kennedy, \& G. P. Fairbrother", Citizenship, 2014.

[55] B. Johnson, and B. Christensen, Educational research: quantitative, qualitative, and mixed approaches, Sage, 2008.

[56] G. Biesta, Mixed methods, in J. Arthur, Research methods and methodologies in education, Sage publications, 2012

[57] D.M. Mertens, Research and evaluation in education and psychology: Integrating diversity with quantitative, qualitative, and mixed methods, Sage publications, 2014

[58] D. Mujis, Doing quantitative research in education with SPSS, Sage, 2010.

[59] L. Cohen, L. Manion, and K. Morrison, Research methods in education (7th edition), Routledge, 2007.

[60] E. Babbie, The basics of social research, Cengage Learning, 2013.

[61] M. Kellett, How to develop children as researchers: A step by step guide to teaching the research process, Sage, 2005.

[62] G. Lindsay , Ethical considerations and legal issues in educational research, Bloomsbury Publishing, 2015.

[63] P. Newby, "Research methods for education", Research methods for education, 2010

[64] P. Hoonakker, and P. Carayon, "Questionnaire survey nonresponse: a comparison of postal mail and internet surveys", International Journal of Human-Computer Interaction, vol. 25, no.5, pp. 348-373, 2009.

[65] K.S. Faught, D. Whitten, and K.W. Green Jr, "Doing survey research on the internet: yes, timing does matter", Doing Survey Research on the Internet: Yes, Timing Does Matter, vol. 44, no. 3, pp. 26-34, 2004. 